\title{
Measuring spiritual belief: development and standardization of a Beliefs and Values Scale
}

\author{
MICHAEL KING ${ }^{1 *}$, LOUISE JONES ${ }^{1}$, KELLY BARNES ${ }^{1}$, JOSEPH LOW ${ }^{1}$, \\ CARL WALKER ${ }^{1}$, SUSIE WILKINSON ${ }^{1}$, CHRISTINA MASON ${ }^{2}$, \\ JULIETTE SUTHERLAND ${ }^{1}$ AND ADRIAN TOOKMAN ${ }^{3}$ \\ ${ }^{1}$ Department of Mental Health Sciences, Royal Free and University College Medical School, \\ University College London, UK; ${ }^{2}$ St. Joseph's Hospice, Hackney, London, UK $;{ }^{3}$ Marie Curie Hospice, \\ Hampstead, London, UK
}

\begin{abstract}
Background. Higher levels of religious involvement are modestly associated with better health, after taking account of other influences, such as age, sex and social support. However, little account is taken of spiritual beliefs that are not tied to personal or public religious practice. Our objective was to develop a standardized measure of spirituality for use in clinical research.
\end{abstract}

Method. We characterized the core components of spirituality using narrative data from a purposive sample of people, some of whom were near the end of their lives. These data were developed into statements in a scale to measure strength of spiritual beliefs and its reliability, validity and factor structure were evaluated in order to reach a final version.

Results. Thirty-nine people took part in the qualitative study to define the nature of spirituality in their lives. These data were used to construct a 47-item instrument that was evaluated in 372 people recruited in medical and non-medical settings. Analysis of these statements led to a 24 -item version that was evaluated in a further sample of 284 people recruited in similar settings. The final 20-item questionnaire performed with high test-retest and internal reliability and measures spirituality across a broad religious and non-religious perspective.

Conclusions. A measure of spiritual belief that is not limited to religious thought, may contribute to research in psychiatry and medicine.

\section{INTRODUCTION}

Although mainstream medicine and psychology have taken little account of spiritual and religious beliefs in the lives of people and their afflictions, since the time of William James there has been a rising interest in measuring such concepts (Hill \& Hood, 1999). Not only did James attempt to define religious belief and understand its origins (James, 1902), he also derived a well-known scientific philosophy that would embrace research into spirituality. $\mathrm{He}$

\footnotetext{
* Address for correspondence: Professor Michael King, Department of Mental Health Sciences, Royal Free and University College Medical School, University College London NW3 2PF, UK. (Email: m.king@medsch.ucl.ac.uk)
}

termed it pragmatism in that it would consider any hypothesis worth testing if consequences useful to life flowed from it (James, 1907). Half a century later Braithwaite, an English moral philosopher, suggested that a (religious) statement need not itself be empirically verifiable, but that it is used in a particular way that is always a straightforwardly empirical proposition (Braithwaite, 1955). Like mathematical statements, religious statements are better expressed in terms of their use than of their method of verification. Subsequently, many others in the twentieth century took research into the consequences of religious belief seriously, particularly with regards to its association with health. 
Higher levels of religious involvement are modestly associated with better health, after taking account of other influences, such as age, sex and social support (Koenig, 1998; McCullough \& Larson, 1999; Koenig et al. 2001). However, religion is often poorly measured in public health research (McCullough et al. 1999) and little account is taken of spiritual beliefs that are not tied to personal or public religious practice (King \& Dein, 1998). Most opinion polls in European countries show that although a high proportion of people will confess to a belief in God, far fewer affirm a religion. A proliferation of scales has been published since Allport and Ross's measure of religious orientation in 1967 (Allport \& Ross, 1967). However, most of this work is based on precepts of North American Christianity and standardization of the instruments has not always been satisfactory (Hunsberger, 1991). We developed an interview (King et al. 1995) and later a short questionnaire (King et al. 2001) as possible measures of spiritual and religious belief. Feedback indicated, however, that it was still insufficient for people who had a non-religious spiritual belief system.

\section{AIM}

The aim was to develop a standardized measure of spirituality that goes beyond conventional religious belief for use in psychological and health research.

\section{Specific objectives}

(1) To explore the meaning of spirituality using semi-structured interviews and focus groups.

(2) To characterize the core components of spirituality arising from these qualitative data.

(3) To apply these components as statements in a scale to measure strength of spiritual beliefs.

(4) To evaluate the reliability, validity and factor structure of such a scale.

\section{METHOD}

Ethical approval was granted by local research ethics committees.

\section{Qualitative data collection}

In order to base our scale securely within dayto-day concepts of spirituality we began with a narrative, qualitative phase. We recruited a purposive sample of people, some of whom had cancer or were caring for someone with cancer. Spiritual issues are likely to be at the forefront of people's minds as they near the end of their lives (Andrykowski et al. 1996). We recruited (1) people with advanced cancer who were receiving end-of-life (palliative) care; and (2) people without cancer chosen from a range of occupational backgrounds. We used focus groups or individual interviews depending on the wishes of the participants. Interviews were semistructured, using prompts such as 'What does your life mean to you?' 'What are your beliefs?' 'What makes your life worthwhile?' 'Do you have any spiritual understanding of your life?' 'How do you express your spiritual beliefs?' and (where appropriate) 'What is important about your spiritual beliefs at this stage in your illness?' to maintain a focus. A third group composed of nurses working in the palliative care units was also recruited into focus groups to talk about their conceptions of how spiritual beliefs affected the dying process. Focus groups were led by L.J. or C.M.

\section{Qualitative analysis and development of a draft scale}

Group and individual interviews were audiotaped, transcribed and analysed thematically. We were interested in people's concepts rather than the detailed manner in which they expressed them. The transcripts were read several times by each senior author (M.K., L.J., S.W. and C.M.) who independently developed themes that they considered relevant. These were discussed in detail and a final set of statements developed. We did not restrict the number of statements at this stage to allow for a broad conception of spirituality and to enable data reduction during standardization. A penultimate set of statements was discussed by members of a patient and carer user group in order to ensure that they could be understood and to reach a consensus on the simplest format in which to frame them. This was a Likert scale in which each statement was followed by five possible responses: strongly agree, agree, neither agree 
nor disagree, disagree, and strongly disagree. Respondents were asked to choose one response for each statement.

\section{Psychometric assessment of scale}

We evaluated a first draft of the scale containing 47 statements in the following populations: (1) patients receiving treatment for cancer in oncology and palliative care services at a central London teaching hospital and hospice; (2) staff at the same institutions as well as those at a hospice in East London; (3) students and staff at a London university and (4) consecutive patients attending three group general practices in central and north London. Inclusion criteria were aged $\geqslant 18$ years and an ability to read English. Exclusion criteria were extreme physical disability, an inability to read English or severe and enduring mental illness. We asked participants to comment on the nature or clarity of statements in the scale or the criterion scale used (see validity below).

In order to measure test-retest reliability, we asked participants to complete the scale again after a 2-week interval. Deciding on an appropriate criterion against which to assess its validity was difficult as our scale covered aspects of spirituality beyond those associated with religious belief or practice. We chose a criterion scale that avoids specific reference to a particular religious faith or denomination. The Intrinsic Religious Motivation Scale is composed of 10 statements about a person's belief, each of which is answered on a 4-point, Likert scale: strongly agree (1), agree (2), disagree (3) and strongly disagree (4). Scores range from 10 to 40, with lower scores indicating higher awareness of spiritual and religious issues. The scale has high internal (Kuder-Richardson $\alpha=0.90)$ and test-retest (91\% agreement) reliability (Hoge, 1972) and correlates closely with Allport's intrinsic religiosity subscale (0.86) (Allport \& Ross, 1967). It has been used in a number of outcome studies in the United States (e.g. Koenig et al. 1998).

\section{Analysis of quantitative results}

We measured test-retest reliability using the weighted kappa statistic, which employs the squared distances for each discrepancy. This corresponds to the least squares approach in calculating intra-class correlation (ICC) and means that the ICC and weighted kappa are algebraically equivalent. We assessed internal consistency using Cronbach's $\alpha$ with item removal. We examined the factor structure of the scale using principal components factor analysis, applying an eigenvalue of $\geqslant 1.0$ as a cut-off for including a factor and Varimax rotation to achieve a final solution. The criteria for removing items from the instrument were: (1) insufficient spread of responses: any statements for which $80 \%$ or more of participants answered at two adjacent points (e.g. strongly agree, and agree) could not provide useful information; (2) statements with reliability equal to or below a weighted kappa of $0 \cdot 5$, towards the lower end of the range indicating only moderate agreement (Altman, 1991); (3) statements that participants indicated were ambiguous or unclear; and (4) statements that did not contribute to the factor structure or the overall variance explained. We explored criterion validity by comparing the pattern of scoring and estimating correlation with scores on the Intrinsic Religious Motivation Scale. We explored the function of the ultimate version of the scale in terms of the demographic and illness characteristics of participants. We analysed the data using STATA version 7 (Stata Corporation, College Station, TX, USA).

\section{RESULTS \\ Qualitative study}

\section{Participants}

Thirty-nine people were recruited. Seven daypatients to palliative care services participated in focus groups and a further four took part in individual interviews. Ten nurses working in the two participating hospices took part in focus groups. Nine in-patients at the same palliative care services participated in individual interviews. A further nine people, aged 28-60 years selected from a variety of vocational and ethnic backgrounds were also interviewed.

\section{Conceptions of spirituality}

A number of people had difficulty defining spirituality but all were able to express in some way or other what it meant for their lives and current circumstances. Principal themes were (1) a search for meaning in the world, in their 
relationships with others and in their personal circumstances; (2) ideas on God, religion, meditation, prayer and life after death; and (3) their reactions to the world around them, particularly the beauty or grandeur of nature. People with advanced cancer did not always refer to their illness but seemed more concerned with the wider meanings of life. However, when directly asked, it was clear that their illness had often made them reflect on similar issues and some believed that their spiritual and religious beliefs had helped them cope with the diagnosis and courses of treatment undertaken.

Group discussions between the senior authors (M.K., S.W., L.J. and C.M.) gave rise to 47 statements that covered the essential aspects of these qualitative data. Where possible we avoided using the term 'spiritual' and instead used other language expressing the concept that arose from the qualitative data. The title Beliefs and Values Scale was chosen as most expressive of the scale's content. The format preferred by participants critiquing the scale at the final focus group was a Likert type with five responses to each item: 'strongly agree', 'agree', 'neither agree nor disagree', 'disagree' and 'strongly disagree'.

\section{Standardization of the Beliefs and Values Scale}

Between September 2003 and January 2005, the instrument underwent two stages of development with 656 participants. In total, 372 people completed version 1 (of whom 262 people completed it on two occasions, 2 weeks apart) and 284 completed version 2 (168 on two occasions). People from a wide range of social and ethnic backgrounds took part (Table 1). People were in the main very responsive to the questionnaire, interested in the study and able and willing to express their views on these difficult concepts, even in busy doctors' surgeries.

\section{Evaluation of first version of scale}

Seven statements were removed from the first version because they attracted a poor spread of responses $(2,8,12,24,31,36,38$; Table 2$)$; one (23) because of poor test-retest agreement; and one (1) because participants often commented that its meaning was unclear. A principal components factor analysis of the remaining 38 statements was conducted in two stages. The first (319 observations) revealed three principal
Table 1. Demographic characteristics of participants

\begin{tabular}{|c|c|c|}
\hline & $\begin{array}{l}\text { Version } 1 \text { of } \\
\text { scale } n(\%)\end{array}$ & $\begin{array}{l}\text { Version } 2 \text { of } \\
\text { scale } n(\%)\end{array}$ \\
\hline \multicolumn{3}{|l|}{ Site of recruitment } \\
\hline Oncology/palliative care patients & $65(17)$ & $100(35)$ \\
\hline Staff or students & $174(47)$ & $26(9)$ \\
\hline GP patients & $133(36)$ & $158(56)$ \\
\hline Missing & - & - \\
\hline \multicolumn{3}{|l|}{ Gender } \\
\hline Male & $111(30)$ & $132(46)$ \\
\hline Female & $260(70)$ & $152(54)$ \\
\hline Missing & $1(0)$ & - \\
\hline \multicolumn{3}{|l|}{ Marital status } \\
\hline Married & $171(46)$ & $145(51)$ \\
\hline Has partner & $62(17)$ & $39(14)$ \\
\hline Single & $92(25)$ & $61(21)$ \\
\hline Divorced/separated & $30(8)$ & $22(8)$ \\
\hline Widowed & $9(2)$ & $13(5)$ \\
\hline Missing & $8(2)$ & $4(1)$ \\
\hline \multicolumn{3}{|l|}{ Ethnicity } \\
\hline White & $312(84)$ & $210(74)$ \\
\hline Black $^{\mathrm{a}}$ & $19(5)$ & $23(8)$ \\
\hline South Asian ${ }^{\mathrm{b}}$ & $17(5)$ & $16(6)$ \\
\hline Chinese & $3(1)$ & $5(2)$ \\
\hline Other & $19(5)$ & $28(10)$ \\
\hline Missing & $2(1)$ & $2(1)$ \\
\hline \multicolumn{3}{|l|}{ Employment status } \\
\hline Employed & $266(72)$ & $116(41)$ \\
\hline Unemployed seeking work & $10(3)$ & $10(4)$ \\
\hline Student & $14(4)$ & $32(11)$ \\
\hline Retired & $46(12)$ & $67(24)$ \\
\hline Home manager & $20(5)$ & $18(6)$ \\
\hline On sick leave & $11(3)$ & $11(4)$ \\
\hline Other & - & $19(7)$ \\
\hline Missing & $5(1)$ & $11(4)$ \\
\hline \multicolumn{3}{|l|}{ Religious belief } \\
\hline Does not observe a religion & $127(34)$ & $76(27)$ \\
\hline Christianity - other & $96(26)$ & $95(33)$ \\
\hline Christianity - Roman Catholic & 70 (19) & $45(16)$ \\
\hline Judaism & $29(8)$ & $21(7)$ \\
\hline Hinduism & $9(2)$ & $12(4)$ \\
\hline Islam & $9(2)$ & $12(4)$ \\
\hline Buddhism & $5(1)$ & $1(0)$ \\
\hline Other & $12(3)$ & $10(4)$ \\
\hline Missing & $15(4)$ & $12(4)$ \\
\hline
\end{tabular}

a Black British, African and Caribbean.

b Indian, Pakistani and Bangladeshi.

factors with eigenvalues $>2.0$ that explained $44 \%$ of the variance. This enabled the removal of 11 further statements $(6,9,10,11,18,19,28$, 29, 35, 43, 47; Table 2) that did not contribute to these main factors. A further principal components factor analysis of the remaining 27 statements (330 observations) revealed three factors with eigenvalues $>1 \cdot 5$, which explained $54 \%$ of the variance. We removed two statements not contributing to the three factors 
Table 2. Content and test-retest reliability of version 1 with reasons for item removal

\begin{tabular}{|c|c|}
\hline Item & $\begin{array}{l}\text { Weighted } \\
\text { kappa }\end{array}$ \\
\hline 1. There are forces in the universe ${ }^{a}$ & $0 \cdot 66$ \\
\hline 2. I see myself as a part of the natural world ${ }^{b}$ & $0 \cdot 57$ \\
\hline 3. Most events in my life are due to chance & $0 \cdot 61$ \\
\hline 4. Reflecting on what life might mean makes me anxious & 0.66 \\
\hline 5. I am a spiritual person & 0.77 \\
\hline 6. It is possible that other worlds exist even though I do not know about them ${ }^{\mathrm{c}}$ & $0 \cdot 67$ \\
\hline 7. I have a spirit or soul that can survive my death & $0 \cdot 88$ \\
\hline 8. Life has no meaning ${ }^{\mathrm{b}}$ & $0 \cdot 70$ \\
\hline 9. I still have the same religious beliefs I was brought up with ${ }^{\mathrm{c}}$ & 0.74 \\
\hline 10. I am clear about what I believe $\mathrm{c}^{\mathrm{c}}$ & 0.66 \\
\hline 11. I have a sense of inner peace ${ }^{c}$ & $0 \cdot 74$ \\
\hline 12. I believe that there is a purpose in life $\mathrm{e}^{\mathrm{b}}$ & $0 \cdot 71$ \\
\hline 13. I believe there is a personal God & $0 \cdot 87$ \\
\hline 14. I think meditation has value & 0.66 \\
\hline 15. God is an all pervading presence & 0.87 \\
\hline 16. I think what happens after I die is determined by how I have lived my life & $0 \cdot 81$ \\
\hline 17. I believe there are forces for evil in the Universe & $0 \cdot 78$ \\
\hline 18. Everything has come about through evolution ${ }^{\mathrm{c}}$ & $0 \cdot 70$ \\
\hline 19. This world is full of suffering ${ }^{c}$ & 0.73 \\
\hline 20. Although I cannot always understand, everything happens for a reason & $0 \cdot 77$ \\
\hline 21. Human physical contact can be a spiritual experience & $0 \cdot 57$ \\
\hline 22. I feel most at one with the world when surrounded by nature & $0 \cdot 70$ \\
\hline $\begin{array}{l}\text { 23. The most meaningful experiences in my life have occurred when I was part } \\
\text { of a large crowd, e.g. a demonstration, sporting event, concert }{ }^{\mathrm{d}}\end{array}$ & $0 \cdot 50$ \\
\hline 24. I feel that life is like a journey ${ }^{b}$ & $0 \cdot 61$ \\
\hline 25. I believe in life after death & $0 \cdot 88$ \\
\hline 26. I am a religious person & 0.87 \\
\hline 27. Religious ceremonies are important to me & $0 \cdot 82$ \\
\hline 28. The most important thing in life is to be good $^{\mathrm{c}}$ & $0 \cdot 69$ \\
\hline 29. Giving love to other people is the most important thing in my life ${ }^{c}$ & 0.68 \\
\hline 30. Life is planned out for you & 0.74 \\
\hline 31. It is important to receive love ${ }^{\mathrm{b}}$ & 0.56 \\
\hline 32. God is a life force & $0 \cdot 80$ \\
\hline 33. At least once in my life, I have had an intense spiritual experience & $0 \cdot 78$ \\
\hline 34. I believe that there is heaven & $0 \cdot 88$ \\
\hline 35. Religious beliefs were part of my upbringing ${ }^{c}$ & 0.83 \\
\hline 36. The most important aspect of life is loving relationships with people ${ }^{\mathrm{b}}$ & $0 \cdot 54$ \\
\hline 37. There is nothing beyond my material existence: I was born and I shall die & $0 \cdot 72$ \\
\hline 38. My relationships with others give most meaning to my life $\mathrm{b}^{\mathrm{b}}$ & 0.61 \\
\hline 39. My upbringing was influenced by a religious tradition ${ }^{\mathrm{c}}$ & $0 \cdot 74$ \\
\hline 40. The human spirit is immortal & $0 \cdot 83$ \\
\hline 41. I think prayer has value & $0 \cdot 83$ \\
\hline 42. I believe in reincarnation ${ }^{c}$ & 0.88 \\
\hline 43. I think physical well being is linked to spiritual well being ${ }^{\mathrm{c}}$ & $0 \cdot 57$ \\
\hline $\begin{array}{l}\text { 44. The most meaningful experiences in my life have occurred through art, } \\
\text { e.g. listening to music, reading, seeing a painting or sculpture or watching a film or play }\end{array}$ & $0 \cdot 64$ \\
\hline 45. I feel most spiritual when I am alone & $0 \cdot 58$ \\
\hline 46. I believe there is a God or gods & $0 \cdot 84$ \\
\hline 47. Science will eventually explain everything ${ }^{c}$ & $0 \cdot 75$ \\
\hline
\end{tabular}

a Statement removed before factor analysis because considered ambiguous/unclear by respondents.

b Statement removed because of inadequate spread of response.

c Statement removed because of minimal contribution to principal factor structure.

d Statement removed because of poor agreement.

e Statement removed after factor analysis because considered ambiguous/unclear by respondents and authors.

(39 and 42; Table 2). Although statement 44 was contained in the three principal factors, we decided to remove it as the examples contained in it suggested more than one meaning. Our concern was confirmed by participants' comments that it was difficult to answer.
Participants' opinions of the scales

Participants' comments also persuaded us to edit statements remaining in version 2. Statement 46 (Table 2) had 'or gods' removed from the stem in version 2, as participants rightly 
Table 3. Content, test-retest reliability and factor structure of version 2

\begin{tabular}{lc}
\hline \hline & Weighted \\
Item & $0 \cdot 61$ \\
\hline 1. I believe most events in my life are due to chance (factor 3) & $0 \cdot 60$ \\
2. Reflecting on what life might mean makes me anxious (factor 5) & $0 \cdot 87$ \\
3. I am a spiritual person & $0 \cdot 84$ \\
4. I believe I have a spirit or soul that can survive my death & $0 \cdot 85$ \\
5. I believe in a personal God & $0 \cdot 69$ \\
6. I believe meditation has value & $0 \cdot 84$ \\
7. I believe God is an all pervading presence & $0 \cdot 76$ \\
8. I believe what happens after I die is determined by how I have lived my life & $0 \cdot 77$ \\
9. I believe there are forces for evil in the Universe & $0 \cdot 74$ \\
10. Although I cannot always understand, I believe everything happens for a reason & $0 \cdot 56$ \\
11. I believe human physical contact can be a spiritual experience & $0 \cdot 73$ \\
12. I feel most at one with the world when surrounded by nature & $0 \cdot 87$ \\
13. I believe in life after death & $0 \cdot 87$ \\
14. I am a religious person & $0 \cdot 84$ \\
15. Religious ceremonies are important to me & $0 \cdot 76$ \\
16. I believe life is planned out for me & $0 \cdot 79$ \\
17. I believe God is a life force & $0 \cdot 80$ \\
18. At least once in my life, I have had an intense spiritual experience & $0 \cdot 92$ \\
19. I believe that there is a heaven & $0 \cdot 73$ \\
20. I believe there is nothing beyond my material existence: I was born & \\
and I shall die (factor 5) & $0 \cdot 80$ \\
21. I believe the human spirit is immortal & $0 \cdot 82$ \\
22. I believe prayer has value & $0 \cdot 64$ \\
24. I believe there is a God & $0 \cdot 93$ \\
\hline
\end{tabular}

Factor 1 in italic; Factor 2 in bold.

commented that it could have two meanings. Participants also reported that universal statements such as 'the human spirit is immortal' could be difficult to answer. For example, I might believe (have faith in the idea; am sure but cannot be certain) that the human spirit is immortal but others might not. Thus, statements $1,7,14-16,20-21$ and 30 in version 1 (Table 2) were qualified by adding 'I believe ...', or substituting it for 'I think ...', to harmonize their style and meaning, and to indicate that we sought the respondent's personal view. We considered it unlikely that a participant might consider that although the rest of the world believed the human spirit was immortal, he or she did not, and this possibility was not suggested by any participant. This issue raises distinctions between I know, I believe and I think, all of which may be interpreted differently. When the opener, I believe, is used in statements such as in this questionnaire, it inevitably contains emotional and moral, as well as intellectual, elements. Participants expressed difficulty in answering statements in the Intrinsic Religious Motivation Scale mainly because it too often assumed a religious belief. Numbers of comments on this scale outnumbered those on our developing scale by three to one.

\section{Evaluation of the second version}

Test-retest reliability of the revised set of 24 statements in a second population was acceptable and no item had a weighted kappa statistic $<0.5$ (Table 3). Cronbach's $\alpha$ for all statements was high at $0 \cdot 93$. No single removal of an item significantly improved internal consistency. A further principal components factor analysis was conducted (249 observations) which, once again, revealed one principal factor with an eigenvalue of 10.5 that explained $44 \%$ of the variance. The remaining statements separated into four further factors with eigenvalues between 1.8 and 1.01 , which explained a further $22 \%$ of the variance. Factor 2 (statements $6,11,12$ ) contained statements referring to spiritual beliefs outside of a religious context. Factors 3-5 contained themes best described as existential anxiety and materialism and those items were not contained further in the overall scale. Factors 1 and 2 (20 statements) constitute the final version (Table 4). Internal consistency of this final scale was 
Table 4. Individual item correlation of the final 20-item version of the Beliefs and Values Scale ${ }^{\mathrm{a}}$ with total score on the Intrinsic Religious Motivation Scale

\begin{tabular}{lc}
\hline \hline Item & $\begin{array}{c}\text { Correlation } \\
\text { coefficient }\end{array}$ \\
\hline 1. I am a spiritual person & $0 \cdot 55$ \\
2. I believe I have a spirit or soul that can survive my death & $0 \cdot 53$ \\
3. I believe in a personal God & $0 \cdot 59$ \\
4. I believe meditation has value & $0 \cdot 17^{*}$ \\
5. I believe God is an all pervading presence & $0 \cdot 64$ \\
6. I believe what happens after I die is determined by how I have lived my life & $0 \cdot 56$ \\
7. I believe there are forces for evil in the Universe & $0 \cdot 47$ \\
8. Although I cannot always understand, I believe everything happens for a reason & $0 \cdot 39$ \\
9. I believe human physical contact can be a spiritual experience & $0 \cdot 13^{* *}$ \\
10. I feel most at one with the world when surrounded by nature & $0 \cdot 05 \mathrm{~N} . \mathrm{S}$. \\
11. I believe in life after death & $0 \cdot 50$ \\
12. I am a religious person & $0 \cdot 52$ \\
13. Religious ceremonies are important to me & $0 \cdot 43$ \\
14. I believe life is planned out for me & $0 \cdot 50$ \\
15. I believe God is a life force & $0 \cdot 54$ \\
16. At least once in my life, I have had an intense spiritual experience & $0 \cdot 49$ \\
17. I believe that there is a heaven & $0 \cdot 57$ \\
18. I believe the human spirit is immortal & $0 \cdot 43$ \\
19. I believe prayer has value & $0 \cdot 58$ \\
\hline \hline
\end{tabular}

All correlations coefficients except those marked $p<0 \cdot 00001,{ }^{*} p<0 \cdot 02,{ }^{* *} p<0 \cdot 05$, N.s. $p>0 \cdot 05$.

Factor 2 in bold, remainder are factor 1.

${ }^{a}$ Each statement of the Beliefs and Values Scale has five possible responses: strongly agree (score 4); agree (3); neither agree nor disagree (2); disagree (1); strongly disagree (0). Possible range of score $0-80$ with higher scores indicating stronger spiritual beliefs.

0.94 and no item removal increased this significantly.

\section{Criterion validity and scoring of the Beliefs and Values Scale}

Pairwise correlation for agreement between total score on the final 20-item Beliefs and Values Scale and the criterion scale score was 0.70 $(p<0 \cdot 00001)$. All individual item pairwise correlations between the criterion scale total score and individual item scores in the Beliefs and Values Scale were significant, with one exception (Table 4). Lowest correlation coefficients occurred with the three statements in factor 2 of the final version and highest with statements that mentioned God. Each statement in this final, 20-item version of the Beliefs and Values Scale has five possible responses: strongly agree (score 4); agree (3); neither agree nor disagree (2); disagree (1); strongly disagree (0). The theoretical range of scores is $0-80$ with higher scores indicating stronger spiritual beliefs.

\section{Variation in scoring on the Beliefs and Values Scale}

Mean scores on the final, 20-item version of the Beliefs and Values Scale varied significantly with sex, religious belief, ethnicity, civil status (Table 5). Mean difference in total score between participants with no form of religious belief (mean score $51 \cdot 7$, s.D. $=13 \cdot 0$ ) and the remainder $(72 \cdot 3$, S.D. $=12 \cdot 1)$ was $20 \cdot 6(t=11 \cdot 9$, $p<0 \cdot 0001)$.

\section{Spiritual experiences}

A total of $182(49 \%)$ respondents completing version 1 , and $133(47 \%)$ completing version 2 , agreed or strongly agreed with the statement that 'At least once in my life, I have had an intense spiritual experience' (question 18 in version 1 and question 16 in the final version). In version $1,31 \%$ of those with no religious affiliation and $55 \%$ of those with an affiliation agreed with this statement, while in the final version, the figures were $30 \%$ and $52 \%$ respectively.

\section{DISCUSSION}

We were able to achieve our four principal objectives. We have developed a reliable and internally consistent scale to assess strength of spiritual beliefs that is based on the narratives and responses of a range of people, from those 
Table 5. Associations between mean scores on the final 20-item version of the Beliefs and Values Scale and participant profile

\begin{tabular}{|c|c|c|c|}
\hline & & $\begin{array}{l}\text { Total scale score } \\
\text { mean (s.D.) }\end{array}$ & Significance \\
\hline Sex & $\begin{array}{l}\text { Men }(120)^{\mathrm{a}} \\
\text { Women (134) }\end{array}$ & $\begin{array}{l}42 \cdot 5(16 \cdot 8) \\
49 \cdot 6(13 \cdot 9)\end{array}$ & $\begin{array}{l}t=3 \cdot 69 \\
p=0 \cdot 0003\end{array}$ \\
\hline Recruitment & $\begin{array}{l}\text { Oncology/palliative care (89) } \\
\text { Staff, student or GP attendee (165) }\end{array}$ & $\begin{array}{l}43 \cdot 9(15 \cdot 5) \\
47 \cdot 5(15 \cdot 7)\end{array}$ & $\begin{array}{l}t=1.73 \\
p=0.08\end{array}$ \\
\hline Religion & $\begin{array}{l}\text { No religion (174) } \\
\text { Christian (117) } \\
\text { Other religion (52) }\end{array}$ & $\begin{array}{l}31 \cdot 7(13 \cdot 0) \\
43 \cdot 2(12 \cdot 0) \\
40 \cdot 4(12 \cdot 3)\end{array}$ & $\begin{array}{l}F=72 \cdot 4 \\
p<0 \cdot 0001\end{array}$ \\
\hline Ethnicity & $\begin{array}{l}\text { White (188) } \\
\text { Black Caribbean, Black British } \\
\text { \& Black African (17) } \\
\text { Indian subcontinent (21) } \\
\text { Other (27) }\end{array}$ & $\begin{array}{l}43 \cdot 5(15 \cdot 4) \\
56 \cdot 8(16 \cdot 0) \\
\\
51 \cdot 5(15 \cdot 0) \\
54 \cdot 1(11 \cdot 8)\end{array}$ & $\begin{array}{l}F=8 \cdot 13 \\
p<0 \cdot 0001\end{array}$ \\
\hline Civil status & $\begin{array}{l}\text { Ever married (157) } \\
\text { With partner (37) } \\
\text { Single (58) }\end{array}$ & $\begin{array}{l}47 \cdot 1(16 \cdot 0) \\
40 \cdot 2(17 \cdot 3) \\
47 \cdot 3(13 \cdot 4)\end{array}$ & $\begin{array}{l}F=3 \cdot 1 \\
p=0 \cdot 05\end{array}$ \\
\hline Employment & $\begin{array}{l}\text { Employed } \\
\text { Remainder }\end{array}$ & $\begin{array}{l}44 \cdot 3(16 \cdot 2) \\
47 \cdot 4(15 \cdot 4)\end{array}$ & $\begin{array}{l}t=1 \cdot 50 \\
p=0 \cdot 13\end{array}$ \\
\hline
\end{tabular}

a $(n)=$ number of participants.

facing a shortened life expectancy and staff who care for them to students and people attending their GPs. Thus the scale's content and format is based on the views of ordinary people and has not been approached as a 'top down', academic exercise. As the scale developed, we subjected each version to rigorous tests of reliability. The advantage of this scale is its ability to tap spiritual beliefs that exist outside of traditional religious contexts. The content of at least 10 questions $(1,2,4,7-10,14,16,18$; Table 5) is distinct from any religious practice or belief and it is noteworthy that $30 \%$ of people without any religious affiliation reported intense spiritual experiences. Finally, the variation in scoring with participants' sociodemographic profile and religious affiliation suggests that the instrument will be sensitive to different settings.

There were a number of limitations to the study. First, standardization was limited to a London population and the instrument requires further testing in other settings. Second, given that these beliefs are likely to be long standing, the test-retest period of 2 weeks was relatively short. However, a longer interval also runs a risk of greater attrition at the retest stage. Third, given that we aimed to develop questions about spiritual beliefs beyond religious belief or practice, it can be argued that its validation against the Intrinsic Religious Motivation Scale is possibly misleading. However, the finding that our spiritual (as opposed to religious) items had lowest correlations with this standard is evidence that they were tapping a broader existential/spiritual domain.

Emile Durkeim (1912), the first great commentator on the possible role of religion in society, considered that the sacred was a transfiguration of social bonds but that faith would still have benefits to people even if they understood it as a social construction. However, our work would suggest that people with no religious affiliation find it difficult to express their spiritual beliefs and experiences. This was clear in the qualitative study and was reflected in the changing language of our instrument as it evolved into the final version. Such concepts may only be measurable by language to a limited extent and are influenced by culture, childhood experience and upbringing. Although there is speculation that our propensity to religious belief is 'hard-wired' (Newburg \& Aquili, 2001), many would argue that the 'spiritual' is a culturally constructed notion whose meaning may change with time. Religion will always be a part of that cultural notion in terms of physical manifestations such as an institution, anointed officials or icons. People want to feel, touch and 
smell their spirituality and the commonest expression of it becomes what we regard as religious (Coleman, 2002). Defining it outside of such symbols is tricky, just as earlier generations had difficulty in defining beauty or the sublime (Burke \& Phillips, 1990).

An ICM poll conducted in 10 countries in 2004 reported that (despite an overall decline in mainstream church attendance) $67 \%$ of people in the UK professed a belief in God or a higher power. Many other countries had even higher rates of spiritual belief and $30 \%$ of atheists across all countries involved reported that they sometimes prayed (ICM Research Ltd, 2004). In successive Harris polls in the United States, around $90 \%$ of people profess a belief in God (Harris Interactive Inc., 2003). This resilience of belief in a post-modern world has led to speculation that it is a human necessity, either as an enduring mechanism to promote social cohesion and help us deal with fear and mortality (Debray, 2004) or as something hardwired into our brains and presumably important for evolutionary reasons (Newburg \& Aquili, 2001). If this is so, we need accurate measures of how people think and feel in this domain of their lives. Although we cannot examine whether a religious statement, such as 'a personal God created the world', is true or false, what the results of such beliefs might be for health and society is a valid, empirical question. A measure of a person's overall spiritual belief that is not limited to religious thought may be useful in increasing our understanding both of health and social service outcomes, and of broader areas of life such a behaviour change and conflict resolution.

\section{ACKNOWLEDGEMENTS}

We thank all the participants, the staff of the participating institutions and general practices, the Camden and Islington Mental Health and Social Care Trust, and The Royal Free Hampstead NHS Trust. We would also like to thank Hélène Seddon Glass and Jeevi Marathiasan for their help with data collection. The study was funded by Marie Curie Cancer Care.

\section{DECLARATION OF INTEREST}

None.

\section{REFERENCES}

Allport, G. W. \& Ross, J. M. (1967). Personal religious orientation and prejudice. Journal of Personality and Social Psychology 5, 432-443.

Altman, D. G. (1991). Practical Statistics for Medical Research. Chapman and Hall: London.

Andrykowski, M. A., Curran, S. L., Studts, J. L., Cunningham, L., Carpenter, J. S., McGrath, P. C., Sloan, D. A. \& Kenady, D. E. (1996). Psychosocial adjustment and quality of life in women with breast cancer and benign breast problems: a controlled comparison. Journal of Clinical Epidemiology 49, 827-834.

Burke, E. \& Phillips, A. (1990). A Philosophical Enquiry into the Origin of our Ideas of the Sublime and Beautiful. Oxford University Press: Oxford.

Coleman, J. A. (2002). Selling God in America: American commercial culture as a climate of hospitality to religion. In Meaning and Modernity: Religion, Polity and Self (ed. R. Madsen, W. M. Sullivan, A. Swidler and S. M. Tipton). University of California Press: Berkeley, CA.

Debray, R. (2004). God: An Itinerary. Verso: London.

Durkheim, E. (1912). The Elementary Forms of the Religious Life: A Study in Religious Sociology. Allen \& Unwin: London.

Harris Interactive Inc. (2003). Harris Poll: the religious and other beliefs of Americans, 2003 (http://www.harrisinteractive.com/ harris_poll/index.asp?PID=359). Harris Interactive. Accessed 26 February 2003.

Hill, P. C. \& Hood, R. W. (1999). Measures of Religiosity. Religious Education Press: Birmingham, AL.

Hoge, D. R. (1972). A validated intrinsic religious motivation scale. Journal for the Scientific Study of Religion 11, 369-376.

Hunsberger, B. (1991). Empirical work in the psychology of religion. Canadian Psychology 32, 497-504.

ICM Research Ltd (2004). What the world thinks of God (http:// news.bbc.co.uk $/ 1 /$ hi/programmes/wtwtgod $/ 3518375$. stm). BBC. Accessed 26 February 2004.

James, W. (1902). The Varieties of Religious Experience: a Study in Human Nature. Longmans: New York.

James, W. (1907). Pragmatism. Longmans, Green: New York.

King, M., Speck, P. \& Thomas, A. (1995). The Royal Free interview for religious and spiritual beliefs: development and standardization. Psychological Medicine 25, 1125-1134.

King, M., Speck, P. \& Thomas, A. (2001). The Royal Free interview for spiritual and religious beliefs: development and validation of a self-report version. Psychological Medicine 31, 1015-1023.

King, M. B. \& Dein, S. (1998). The spiritual variable in psychiatric research. Psychological Medicine 28, 1259-1262.

Koenig, H. G. (1998). Handbook of Religion and Mental Health. Academic Press: San Diego, CA.

Koenig, H. G., George, L. K. \& Peterson, B. L. (1998). Religiosity and remission of depression in medically ill older patients. American Journal of Psychiatry 155, 536-542.

Koenig, H. G., McCullough, M. E. \& Larson, D. B. (2001). Handbook of Religion and Health. Oxford University Press: Oxford, New York.

McCullough, M. E. \& Larson, D. B. (1999). Religion and depression: a review of the literature. Twin Research 2, 126-136.

McCullough, M. E., Larson, D. B., Koenig, H. G. \& Lerner, R. (1999). The mismeasurement of religion in mortality research. Mortality 4, 183-194.

Newburg, A. \& Aquili, E. (eds). (2001). Why God Won't Go Away: Brain Science and the Biology of Belief. Ballantine: New York. 
Reproduced with permission of the copyright owner. Further reproduction prohibited without permission. 